\title{
Exploring Motivational Drivers in the Corporate Sector Toward Green Purchasing and Promoting Upcycled Products to Adopt Environmentally Responsible Business Practices
}

\author{
Prasadi H.L.A. ${ }^{*}$, Weerawardana P.A.H. ${ }^{2}$ and Jayasinghe R.A. ${ }^{2}$ \\ ${ }^{I}$ Center for Sustainability, Department of Forestry and Environmental Science, University of Sri \\ Jayewardenepura, Sri lanka \\ ${ }^{2}$ Australian-Sri Lankan University partnerships Project, University of Moratuwa, Sri Lanka \\ *prasadi@sci.sjp.ac.lk
}

\begin{abstract}
The global and local environmental problems are becoming critical where natural environment has turn out to be a perplexing issue to business organisations, specially the business operations like sourcing, manufacturing and logistics. As a result, business operations are subject to increasing pressures and scrutiny from various stakeholders inside and outside the organisation such as government agencies, workers, public, and not-for-profit groups. Waste upcycling is one of the most sustainable practices that any business entity could adopt in order to promote environmentally responsible business practices. Upcycling is a process where already used materials are transformed into something of greater value and/or higher quality in their second life. The concept of upcycling has received worldwide attention from businesses in recent years. However, this is a fairly new concept in Sri Lanka. The rationale aim of this study was to determine the foremost reasons that motivate purchase intention of green products for different corporate events. Further, the study investigated the willingness to accept new upcycled products by corporate customers. Data were collected through a questionnaire distributed among 35 corporations. Results indicate that an increase environmental awareness, eco-labels becoming a life style, new legislations on waste and eco-cultural value (man-nature harmonization) have greatly influenced the green purchase intentions in business organizations. In addition, the findings reveal that upcycled products in Sri Lanka are more visible in a niche market as environmental education and life style has a significant positive impact on eco-consumerism. It further offers insights for suppliers, manufacturers, marketers and policy makers who are concerned on encouraging green purchasing intentions which require differentiated strategic marketing plan than other conventional products.
\end{abstract}

Keywords: Upcycling, Green Ppurchase, Eco-consumerism

Proceedings of the International Forestry and Environment Symposium 2016, Department of Forestry and Environmental Science, University of Sri Jayewardenepura, Sri Lanka. 